\title{
Cycle Synchronization and Economic Convergence in ECCAS Zone
}

\author{
Ulrich Kevin Kamdoum Kamwa \\ International Center for Research in Economics and Management for Development (ICREMD), OMAR BONGO University, \\ Libreville, Gabon \\ Email: ulrichkamwa@gmail.com
}

How to cite this paper: Kamwa, U. K. K. (2020). Cycle Synchronization and Economic Convergence in ECCAS Zone. Theoretical Economics Letters, 10, 1146-1165. https://doi.org/10.4236/tel.2020.105068

Received: August 18, 2020

Accepted: October 24, 2020

Published: October 27, 2020

Copyright $\odot 2020$ by author(s) and Scientific Research Publishing Inc. This work is licensed under the Creative Commons Attribution International License (CC BY 4.0).

http://creativecommons.org/licenses/by/4.0/

\begin{abstract}
This article is part of the analysis of business cycles and the convergence of integrated economies. In contrast to work on the convergence of business cycles in a monetary union, we study the synchronization of business cycles within the Economic Community of Central African States (ECCAS), characterized by heterogeneity monetary. Thus, we first extract cycles from GDP using the Baxter and King (1999) filter; then we date the cycles using the Bry and Boschan (BB, 1971) algorithm, and finally we measure cyclical co-movements using the Harding and Pagan (2006) concordance index. Furthermore, sigma-convergence is used to measure the degree of closeness over time of the identified economies, on the one hand, and beta-convergence to measure their adjustment process over time with respect to a reference value, on the other hand. The results obtained attest to the asynchronous nature of business cycles in the ECCAS zone over the period from 1990 to 2018. Thus, a weak trend towards convergence, both nominal (inflation, basic budget balance, public debt ratio) and real (GDP/capita and GNI/capita) has been observed since 2001 .
\end{abstract}

\section{Keywords}

Business Cycle, Baxter and King Filter, Economic Convergence

\section{Introduction}

The current economic situation, marked by the Covid19 pandemic, has revived the problems relating to the management of economic shocks (Rodrik, 2014; Tornell \& Lane, 1999) and the resilience of integrated economies (Krugman, 1993; Watson, 1994). Thus, the global nature of this exogenous shock directs this debate towards the synchronization of cycles and the convergence of integrated 
economies (Creel, 2018).

Theoretical lessons underline the importance of studying the convergence of integrated economies (Duval, Cheng, Hwa Oh, Saraf, \& Seneviratne. 2014). Indeed, two approaches structure the debate on the synchronization or otherwise of economic cycles. The first, initiated by Frankel and Rose (1998), presents the synchronization of business cycles as an endogenous criterion of optimality that reduces the impact of asymmetric shocks (Penot, Polin, \& Setz, 2000). Indeed, according to these authors, one of the criteria put forward is the cost associated with asymmetric shocks likely to affect the economies of the member countries of an economic area. These costs are all the higher the more as national economic cycles are asynchronous. The functioning of a monetary union is therefore conflictual insofar as countries at different phases of their economic cycles are confronted with different monetary requirements. On the other hand, highly correlated national economic cycles help to conduct a satisfactory monetary policy for the benefit of the countries of the union. Indeed, Frankel and Rose (1998) argue that monetary union increases trade, which in turn promotes the correlation of member countries' business cycles. The second approach is based on the work of Krugman (1993) in international trade theory. The author shows that a monetary union is a source of specialization and weakens the monetary co-movement of business cycles. Indeed, according to the author, monetary and regional integration leads to specialization and geographical concentration of industries, which subsequently affects the mobility of production factors and economic growth in the medium and long term. Thus, the mobility of labor and capital amplifies economic fluctuations (asymmetric shocks) in the region and tends to create divergence in economic growth rates over time.

Empirically, studies on the assessment of the synchronization of the business cycles in a group of countries can be classified into two categories, depending on the methodology used. The first category includes work following the studies by Frankel and Rose (1998). They proceed by first calculating trade intensity and secondly investigating the impact of this intensity on the business cycle synchronization index. Indeed, Calderon, Chong and Stein (2003) use a gravity model to calculate a cycle correlation coefficient. The results show that the impact of trade integration on cycle synchronization is greater among industrialized countries than among least developed countries. Shin and Wang (2004) extend the analysis of the link between trade intensity and the cycle correlation index by seeking to identify trade intensity through four channels: intra-industry trade, inter-industry trade, excess demand and political coordination. Their study shows that intra-industry trade is the main explanatory variable of the product correlation index. Rana (2007), who took the equation specified by Shin and Wang (2004) and estimated it using the instrumental variables, confirms the result of the latter. More recently, Duval, Saiki and Kim (2014) also confirm the impact of business integration on the synchronization of product cycles. As regards the studies in the second category, Lucia (2008) and Chen and Mills (2009) find in 
the case of the European Monetary Union (EMU) that business cycle synchronization is of the order of 0.65 . The results of the studies in the second category are as follows. This index is higher, reaching 0.85 , for a sample of EMU countries (Germany, France, Italy, Spain). However, Ekomie (1999), Carmignani (2010) and Kane (2013), who are looked respectively at the case of the Central African Economic and Monetary Community (CEMAC) and the West African Economic and Monetary Union (WAEMU), find weak business cycle synchronization in the two monetary unions.

In summary, these theoretical and empirical lessons demonstrate the importance of studying the level of synchronization of business cycles in an economic zone. This interest is reflected not only in the appreciation of the costs of abandoning monetary independence (they are all the higher the weaker the synchronization), but also in the adaptation of monetary policies according to these costs. Thus, the work presented admits the hypothesis that the synchronization of cycles is not a static phenomenon. However, despite this large volume of empirical work on the synchronization of business cycles in integrated economies (EU, WAEMU, CEMAC), to our knowledge, there are no studies that focus on both business cycles and economic convergence in the countries of the Economic Community of Central African States (ECCAS).However, this study is acutely relevant in such a context for at least two (02) reasons:

1) First, the exposure of ECCAS countries to exogenous shocks. Indeed, according to the 2017 report of the "Economic Outlook for Central Africa", nine of the community's eleven countries are exporters of oil, mineral and mining resources (diamonds, copper, iron, manganese, cobalt, etc.), some of which are world-class deposits. Products whose price on the international market is highly volatile and therefore influences the behavior of the gross domestic product ${ }^{1}$.

2) Second, the continuation of the continental integration project (the Continental Economic Zone). The Economic Community of Central African States (ECCAS), with a population of about 187 million, brings together economies that do not share the same currency and are quite heterogeneous in terms of size (population), wealth (GDP), natural and cultural ${ }^{2}$ endowments (history, official language and customs).

Thus, in view of this economic and structural disparity observed in the ECCAS zone, and with reference to the work of Krugman (1993), Frankel and Rose, (1999), it seems quite legitimate to question the level of synchronization of economic cycles in the ECCAS space.

However, according to Tavera (1999) and Bamba (2004), the lack of a unified economic theory and a coherent methodology for economic convergence makes it difficult to evaluate and quantify. To this end, it is necessary first to analyze the foundations of the concepts of convergence and the economic cycle (Fuss,

${ }^{1}$ In other words, in 2017, oil and mining represented the largest share of the regional economy, with a contribution to regional GDP of nearly 55\% (Economic Outlook for Central Africa 2017).

${ }^{2}$ Culture highlights the level of consciousness of society, the different languages used (French, Spanish and Portuguese) and the history of economic and political facts. 
1999) and secondly to reflect on the role of its various components, including the dynamics of the convergence process and the adjustment mechanisms in the post-shock period.

With reference to the "European Union" case, the taking into account of these different concerns has led both on the setting of the convergence criteria observed today and on the nature of the adjustment process (Bénassy-Quéré, Coeuré, Jacquet, \& Pisani-Ferry, 2004). Thus, it should be recalled that a regional integration process is generally based on many objectives, political, economic and social at the same time. Among these, the intermediate objective of economicconvergence is regularly put forward in order to benefit from the advantages of an integrated economic zone. Indeed, too great a heterogeneity of the grouped economies creates undesirable rigidities. The migration crisis in the European Union is a clear illustration of this, supporting the need for convergence.

However, the case of the ECCAS region remains singular in several respects. It brings together countries that do not share the same currency and integrates three distinct sub-regions ${ }^{3}$ including CEMAC, COMESA and SADEC. Table 1 in the appendix presents some specific features of the ECCAS economies. In this context, this study uses Cameroon, Gabon and Equatorial Guinea, which together account for nearly $75 \%$ of sub-regional ${ }^{4}$ GDP, as reference countries for the CEMAC region, and Angola, the Democratic Republic of the Congo and Rwandaas non-CEMAC countries. That is a sample of six countries representing nearly $90 \%{ }^{5}$ of the wealth generated in the ECCAS zone. In this regard, it is interesting to examine the synchronization or otherwise of business cycles and the convergence of the economies of the Economic Community of Central African States.

The present reflection is therefore a contribution to the analysis of the links between the business cycle and economic convergence within an economic zone, in that it makes it possible to determine the synchronous or asynchronous nature of economic cycles, on the one hand, and to analyze the nominal and real convergence of integrated economies, on the other. However, it is argued here as a hypothesis that, because of the differences observed in the level of diversification of the economiesstudied, economic cycles are asynchronous and that there is economic divergence within the Community. This could explain the low resilience observed in the sample countries in times of shocks.

The rest of the work is organized as follows: section 2 presents the methodology used to measure business cyclesynchronization and convergence of economies, section 3 performs an empirical analysis by presenting the main results obtained and the associated interpretations. We conclude in the fourth section with a conclusion and policy implications.

${ }^{3}$ CEMAC: Cameroon, Congo, Gabon, Equatorial Guinea, Central African Republic and Chad; SADEC: Angola; COMESA: Burundi, Rwanda and Democratic Republic of Congo.

${ }^{4}$ Central African Economic and Monetary Community (CEMAC), 2019.

${ }^{5}$ Statistical Yearbook for Africa, 2019. 
Table 1. ECCAS economies.

\begin{tabular}{|c|c|c|c|c|}
\hline Country & Currency & $\begin{array}{l}\text { Population } \\
\text { (thousands) }\end{array}$ & $\begin{array}{c}\text { GDP } \\
\text { (millions of } \$ \text { ) }\end{array}$ & $\begin{array}{l}\text { Share of GDP in } \\
\text { ECCAS (in\%) }\end{array}$ \\
\hline Angola & Kwanza & 29,784 & 122,124 & 48 \\
\hline Burundi & Burundian Franc & 10,864 & 3172 & 1 \\
\hline Cameroon & Franc CFA & 24,054 & 34,923 & 14 \\
\hline Central african republic & Franc CFA & 4659 & 1949 & 1 \\
\hline Republic of Congo & Franc CFA & 5261 & 8701 & 3 \\
\hline Democratic Republic of Congo & Congolese franc & 81,340 & 37,642 & 15 \\
\hline Gabon & Franc CFA & 2025 & 15,014 & 6 \\
\hline Equatorial Guinea & Franc CFA & 1268 & 12,294 & 5 \\
\hline Rwanda & Rwandan franc & 12,208 & 9135 & 4 \\
\hline Sao Tome and Principe & Dobra & 204 & 393 & 0 \\
\hline Chad & Franc CFA & 14,900 & 9871 & 4 \\
\hline$E C C A S$ area & & 186567 & 255,218 & \\
\hline which EMCCA zone & Franc $C F A$ & 52,167 & 82,752 & 32 \\
\hline
\end{tabular}

Source : ceeac-eccas.org; 2017.

\section{Methodology}

Several empirical studies have examined the synchronization of business cycles in monetary unions.

As a methodology used for the study of cycles, the literature generally retains the algorithm of Bry and Boschan (BB, 1971) for the dating of cycles and the concordance index of Harding and Pagan (2006) for the measurement of cyclical Co-movements over a given time series. Concerning economic convergence, two levels of analysis are generally presented. The first is whether economies are tending towards a reference value or a stationary state: this is beta-convergence; and second is to measure the degree of convergence over time between several economies. Or to specify whether the economies of a zone converge with each other: this is sigma-convergence.

\subsection{Measuring Business Cycle Synchronisation}

Inspired by the work of Beine, Rand and Tarp (2002), Allegret and Zantman (2006), we proceed to the datebusiness cycles using the algorithm of Bry and Boschan (1971) on the one hand and analyze the synchronization of the cycles identified by the concordance index of Harding and Pagan (2006) on the other hand.

\subsubsection{Dating Business Cycles}

The algorithm of Bry and Boschan (1971), allows the identification of turning 
points (peaks and troughs) of cycles according to the tradition of Burns and Mitchell (1946).

It can be summarized in three main steps:

1) In determining the candidate turnaround points for an annual series $Z_{t}$, the following rule applies:

- $Z_{t}$ admits a t-peak if: $Z_{t} \succ Z_{t-1} ; Z_{t} \succ Z_{t+1}$

- $Z_{t}$ admits a t-rough if: $Z_{t} \prec Z_{t-1} ; Z_{t} \prec Z_{t+1}$

2) The disqualification of turning points located more or less six months from the beginning or end of the series;

3) Checking a rule of perfect alternation between peaks and troughs so that in the presence of a double trough, the smallest value is chosen. In the presence of a double peak, the highest value is chosen.

Once dated, the cyclic component can be characterized from the calculation of the following main indicators:

a) Depth is the magnitude of the recession or expansion, and it is defined by:

$$
\text { Depth }=\frac{V_{p}-V_{c}}{V_{p}}
$$

where $V_{p}$ is the value of the series at the peak and $V_{c}$ is the value at the trough of the cyclic component.

b) Severity summarizes the information contained in duration and depth. In addition, it measures the loss (respectively the gain) realized by a variable during a contraction phase (respectively an expansion phase).

It is calculated according to the formula:

$$
\text { Severity }=\text { Depth } \times \text { Duration } \times 0.5
$$

\subsubsection{Harding and Pagan's Concordance Index (2006)}

This method ${ }^{6}$, based directly on the measurement of turnaround points, is defined as follows: for two indicators $\mathrm{X}$ and $\mathrm{Y}$ of two economies with the same sample size " $N$ ", the concordance index is determined by the following formula:

$$
I C_{x y}=\frac{1}{N} \sum_{i=1}^{N}\left[S_{X, t} S_{Y, t}+\left(1-S_{X, t}\right)\left(1-S_{Y, t}\right)\right]
$$

where for a $S_{Z t}=1 I_{\left[A Z_{t} \succ 0\right]}$ given $Z_{t}$ series.

So that:

If $I C_{x y}=1$, the $\mathrm{X}$ and $\mathrm{Y}$ series are perfectly in phase. In other words, their expansion and contraction phases are perfectly juxtaposed;

When $I C_{x y}=0$, the $\mathrm{X}$ and $\mathrm{Y}$ series are always in opposite phases, and there is a perfect anti-concordance between the two series. This coefficient thus makes it possible to verify whether the indicators studied are pro-cyclical or counter-cyclical;

${ }^{6}$ This method is used several times in IMF reports, we have as an example the World Economic Outlook, April 2009, chapter 3. 
Indeed, if $I C_{x y}=1$, it is said that the series are exactly pro-cyclical then, while a value close to zero indicates a counter-cyclical situation.

\subsection{Measuring Economic Convergence}

The study of convergence is central to the comparison of the growth paths of the economies of different countries (Baumol, 1986; Mankiw, Romer, \& Weil, 1992). However, the economic literature distinguishes between two main methods of assessing convergence: $\beta$-convergence, which focuses on the existence of a convergence mechanism, and $\sigma$-convergence, which is based on the evolution of the dispersion of the GDPs of different economies over time (Barro \& Sala-i-Martin, 1990).

According to Nguyen (1996), economic convergence can be defined as the narrowingof gaps between sets of indicators for several countries. For this purpose, it can take several forms, the main ones being nominal and real convergence. For Martin and Velasquez (2001), nominal convergence is defined as the process of bringing together over time the nominal variables indicative of macroeconomic stability, namely: inflation rates, public debt or deficit ratios in relation to the gross domestic product and interest rates. Nominal convergence also occurs when these variables tend towards a reference value.

Real convergence, on the other hand, is the relative improvement in living standards within a group of countries. It establishes a homogenization of living conditions that leads to economic and social cohesion. In practical terms, it translates into a reduction in the dispersion of per capita income levels among the countries in a zone over time.

The following functional form is used to analyze the real convergence between a group of countries:

$$
\frac{\Delta Y_{i t}}{Y_{i, t-1}}=\alpha+\beta * \log \left(Y_{i 0}\right)+u_{i t}
$$

With:

- $\frac{\Delta Y_{i t}}{Y_{i, t-1}}$, the growth rate of the country's GDP per capita $i$;

- $Y_{i 0}$, the GDP per capita (GDP/capita) of country $i$ in its initial state;

- $t$ = time;

- $u=$ the error term or the hazard (normally and independently distributed).

We know that for a $\beta$ estimatednegative, between 0 and 1 in absolute value, and statistically significant (at the 5\% threshold for example), there is real convergence (the differences in the GDP/capitaof the countries will, on average, tend to disappear); on the contrary, it is real divergence. In addition to the estimation of the relationship (4), to test real convergence, one can also observe the temporal evolution of the standard deviation of (GDP/capita) of the countries in other to judge whether they are moving closer together or if they are diverging. If there is a decrease in the standard deviation (a sign that the countries' 
GDP/capita is moving closer together), it is concluded that there is real convergence in the area under consideration; on the other hand, if the standard deviation increases (meaning that the countries' GDP per capita differences are widening), it is generallyconsidered that there is divergence. Indeed, the absence of real convergence or divergence, if the arguments put forward in endogenous ${ }^{7}$ growth models are taken into account, may be due to the various effects of exogenous $^{8}$ shocks on the economies of a union; in other words, the almost total absence of freedom of movement of goods and factors of production.

In an empirical framework, convergence should be measured at two levels. On the one hand, the question is whether an economy is tending towards a reference value or a steady state: This is beta-convergence. Thus, there is convergence if there is a mechanism for correcting deviations from the reference value. In the case of multilateral surveillance, it is a question of verifying whether the indicator under consideration converges towards the fixed norm ${ }^{9}$ that represents equilibrium. On the other hand, it is necessary to specify whether the economies of a zone are converging with each other: This is the sigma-convergence. Its analysis is based on the study of the temporal evolution of the dispersion of the series of indicators (nominal or real) under consideration. A classic measure consists of calculating the variance or standard deviation of the series; if the indicator of dispersion decreases, it means that the countries are moving closer together.

\subsubsection{The Beta Convergence}

Beta convergence is a process of adjustment, over time, of individuals (economies, countries, regions, etc.) towards the same growth path or reference value. In this study, in order to verify the beta convergence hypothesis, the following relationship is estimated on panel data:

$$
\frac{\Delta Y_{i t}}{Y_{i, t-1}}=\alpha+\beta^{*} \log \left(Y_{i 0}\right)+\gamma X_{i t}+\varepsilon_{i t}
$$

Thus, $\frac{\Delta Y_{i t}}{Y_{i, t-1}}$ the growth rate of the Gross Domestic Product per capita (GDP/capita) of country " $\mathrm{i}$ " is regressed to its initial level $\left(Y_{i 0}\right)$, while controlling for differences in the steady state (differences in preferences, technologies,

\footnotetext{
${ }^{7}$ Contrary to the neoclassical view, the theories or models of endogenous growth, initiated by the models of Romer (1986) and Lucas (1988), do not predict the convergence between rich and poor countries, even when the movements of goods and capital are free. Indeed, by rejecting the hypothesis of diminishing returns on capital, these models exclude the economic mechanism that generates the process of convergence. In places, this work therefore considers at best only a persistence of disparities; because mechanisms linked to the presence of increasing returns reinforce the initial advantages characterizing the countries. Moreover, Lucas (1988) even thinks that openness and economic integration can delay regional convergence because trade between countries can lead them to specialize in sectors where they have a comparative advantage, but where low learning effects are present.

${ }^{8}$ Oil shock, financial crisis, health crisis, etc.

${ }^{9}$ The convergence criterion corresponds to the community standard defined by the Pact.
} 
population growth rates, etc., which constitute the variable " $X_{i t}$ "). Note that expression (5) is different from expression (4) by the presence of a " $\gamma X_{i t}$ " component, which is justified by the homogenization of conditions at the initial level of development (technological development, human capital, etc.).

However, note that:

- If $\gamma=0$ (statistically insignificant): we are talking about absolute real convergence, with $\beta \neq 0,(\beta<0)$ et $0<|\beta|<1$;

- If $\gamma \neq 0$ (statistically significant): we speak of conditional or relative real convergence, with $\beta \neq 0,(\beta<0)$ et $0<|\beta|<1$.

Similarly, estimating an "attraction relationship" as follows:

$$
\Delta Y_{t}=\beta *\left(Y_{t-1}-Y^{*}\right)
$$

Equation (6) verifies the presence of an adjustment mechanism over time of the economic variables towards a reference value $\left(Y^{*}\right)$ considered to be "attractive". Note that if $\beta<0$ et $\beta \neq 0$ (statistically significant), that implies that there exists a mechanism for correcting deviations from the reference value, that is to say that there is convergence (beta convergence).

\subsubsection{The Sigma Convergence}

Sigma convergence measures the degree of rapprochement, over time, between several individuals (economies), with regard to one or more indicators or criteria. In practice, one often observes the evolution of the dispersion of the series considered. Thus, note that there is convergence of the whole sample if this dispersion decreases; otherwise, there is divergence.

As an indicator of dispersion, the variance or standard deviation of the series is generally considered. The formulas are given as follows:

$$
\sigma_{t}(c)=\sqrt{\sum_{i=1}^{n} \frac{\left(c_{i, t}-\bar{c}\right)^{2}}{n}}
$$

With $\bar{c}=$ annual average of countriesachievements ${ }^{10}$.

And

$$
V_{t}(X)=\sqrt{\sum_{j=1}^{n} n_{j}\left(X_{j, t}-\bar{X}_{t}\right)^{2}}
$$

where the average $\bar{X}_{t}=\sum_{j=1}^{n} n_{j}\left(X_{j, t}\right)$ is weighted by the GDP of each country to take into account its economic weight $n_{j}$. The decrease over time shows a tendency to move closer to the average without guaranteeing its significance. Thus, the test of the convergence hypothesis of Carree and Klomp (1997) is carried out. It makes it possible to assess the significance of such a process by comparing the value of the variance at the beginning and end of the period.

According to the existing literature, the convergence of economies could be apprehended through the analysis of reference macroeconomic indicators,

${ }^{10}$ The annual average takes better account of the fact that countries' economic structures are not identical. It can also be considered the best performance of achievements in the year, or the standard set in the framework of multilateral surveillance. 
namely the inflation rate, public debt, the budget balance, GDP per capita and national income per capita (Martin \& Velasquez, 2001). The aim of this subsection is therefore to analyze this convergence in both nominal and real terms ( $\sigma$ convergence and $\beta$ convergence). Specifically, we make statistical and econometric estimates on panel data by measuring both sigma-convergence and beta-convergence for the identified ${ }^{11}$ nominal and real criteria respectively.

The indicator of dispersion used in this study to measure sigma-convergence is the standard deviation (Equation (7)), which measures the degree of closeness over time between economies. For beta-convergence which measures the process of adjustment over time of the economies with respect to a reference value (community standard); the Panel regression model (5) is used. Thus, there is convergence if there is a mechanism for correcting deviations from the reference value, that is, if $\beta$ is negative and statistically significant. To this end, in order to study the state of nominal convergence in the ECCAS zone, three nominal criteria are used, namely the inflation rate, the public debt rate and the basic budget balance.

\section{Results and Interpretations}

Our study covers six ECCAS countries and is based on annual data from the World Bank 2019 over the period 1990 to 2018, i.e. 28 years. For this purpose, we take Cameroon, Gabon and Equatorial Guinea as reference countries for the CEMAC area, and Angola, the Democratic Republic of the Congo and Rwandaas non-CEMAC ECCAScountries.

\subsection{Evaluation of the Synchronization of Business Cycles in the ECCAS Zone}

Using the methods presented above, we obtain in the appendix graphs that highlight the cyclical component of real GDP for each of the economies identified (appendix 1), on the one hand, and the dating of the cycles (appendix 2) by country, on the other hand.

The following key lessons can be draw from this process:

1) On average, there were four major business cycles in ECCAS countries over the period 1990-2018. The average length of a cycle is about two years in Angola, Cameroon and Equatorial Guinea. It is three years in Gabon, the Democratic Republic of the Congo and five years in Rwanda;

2) The phases of major recessions correspond broadly to the periods 1991-1993 for Angola, 2014-2017 for Cameroon, 2010-2017 for Gabon, 2008-2010 for Equatorial Guinea, 1995-1997 in the DRC and 1992-1994 for Rwanda. However, over the period studied, the most severe recession was observed in Angola and the contraction was less severe in the Democratic Republic of Congo.

Thus, graph 7 below presenting the evolution of business cycles in the ECCAS zone highlights two major results:

${ }^{11}$ Drawing inspiration from the multilateral surveillance mechanism in the CEMAC zone. 
Graph 7: Evolution of business cycles in the ECCAS zone

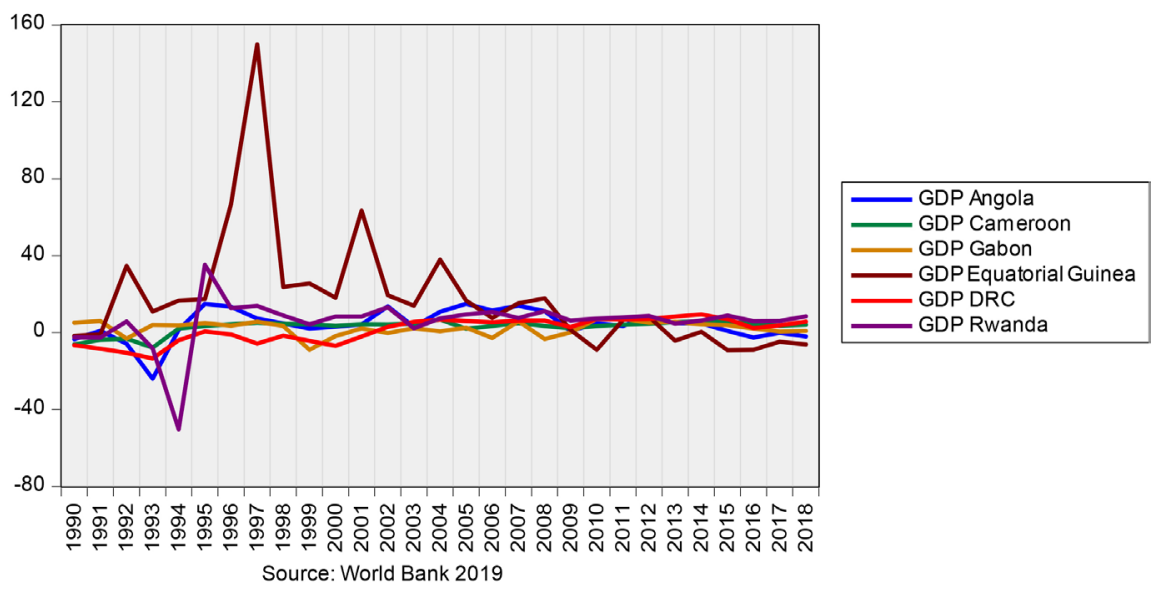

1) Over the period from 1990-2007, cyclical business movements were asynchronous in the economiesidentified;

2) Leaving aside Equatorial Guinea aside, however, we observe over the period $2008^{12}$ to 2018 a relative synchronization of the Angolan, Cameroonian, Gabonese, Congolese and Rwandan cycles. This weak synchronization is explained by increasingly greater economic diversification and a relative improvement in their resilience in times of shocks.

Now, let us also measure the correlation of the business cycles identified by applying the method of Harding and Pagan (2006). Having retained 6 countries, we obtain 15 cross correlations. The average of these 15 correlations provides a synthetic measure of the average degree of synchronization prevailing at a given point in time.

The results obtained are presented in Table 2 below:

Looking at Table 2, we see a low degree of synchronization of community's economies, with an average of $26 \%$. In fact, we note that Angola, Cameroon, Gabon and the Democratic Republic of the Congo, together achieve an average synchronization of $37 \%$. Similarly, the Rwandan economy seems less synchronized with those of Gabon and the Democratic Republic of the Congo (15\%). Cameroon also shows fairly moderate synchronization with the Rwandan economy (19\%). As for Equatorial Guinea, there is a degree of cyclical synchronization close to $22 \%$ with Gabon, the Democratic Republic of the Congo and Rwanda.

\subsection{Determination of the Degree of Convergence in the ECCAS Zone}

For each of the variables identified, the sigma-convergence is calculated for all the countries in the zone in order to verify the state of reconciliation of the economies (Table 3). However, in the case of beta-convergence, it was calculated for each country according to each of the three nominal criteria (Table 4).

${ }^{12}$ Either since the financial, economic and social crisis of 2008. 
Table 2. Degree of synchronization among ECCAS countries (1990-2018) in percent (\%).

\begin{tabular}{|c|c|c|c|c|c|c|}
\hline ECCAS countries & Angola & Cameroon & Gabon & $\begin{array}{l}\text { Equatorial } \\
\text { Guinea }\end{array}$ & $\begin{array}{l}\text { Democratic Repub- } \\
\text { lic of Congo }\end{array}$ & Rwanda \\
\hline Angola & - & 37 & 37 & 30 & 37 & 26 \\
\hline Cameroon & 37 & - & 22 & 33 & 30 & 19 \\
\hline Gabon & 37 & 22 & - & 22 & 30 & 15 \\
\hline Equatorial Guinea & 30 & 33 & 22 & - & 22 & 22 \\
\hline Democratic Republic of Congo & 37 & 26 & 30 & 22 & - & 15 \\
\hline Rwanda & 26 & 19 & 15 & 22 & 15 & - \\
\hline
\end{tabular}

Source: Author's calculations.

Table 3. Sigma-convergence applied to nominal indicators.

\begin{tabular}{cccccc}
\hline Sigma-convergence & 2001 & 2006 & 2011 & 2016 & 3.64 \\
Inflation & 159 & 5 & 1.68 & 2.16 \\
Basic fiscal balance & 6.25 & 14 & 0.94 & 0.81 \\
Public debt ratio & 4 & 0.52 & 1.46 \\
\hline
\end{tabular}

Table 4. Calculations of beta-convergence applied to nominal indicators.

\begin{tabular}{|c|c|c|c|}
\hline BETA & Base Budget balance & Inflation rate & Public debt ratio \\
\hline Angola & $0.56^{* * *}$ & $(-0.82)^{\star * *}$ & 0.21 \\
\hline Cameroon & $0.62^{* * *}$ & $1.05^{* * *}$ & 0.15 \\
\hline Gabon & 0.23 & $1.31^{* * *}$ & $0.79^{* * *}$ \\
\hline Equatorial Guinea & 0.26 & $0.45^{* * *}$ & 0.04 \\
\hline Democratic Republic of Congo & $0.39^{* * *}$ & $(-0.43)^{* * *}$ & $0.93^{* * *}$ \\
\hline Rwanda & $0.72^{\star * *}$ & $0.7^{\star * *}$ & 0.04 \\
\hline
\end{tabular}

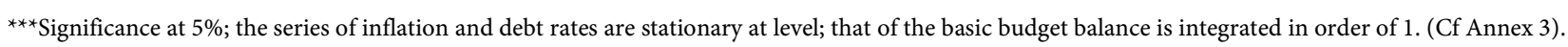

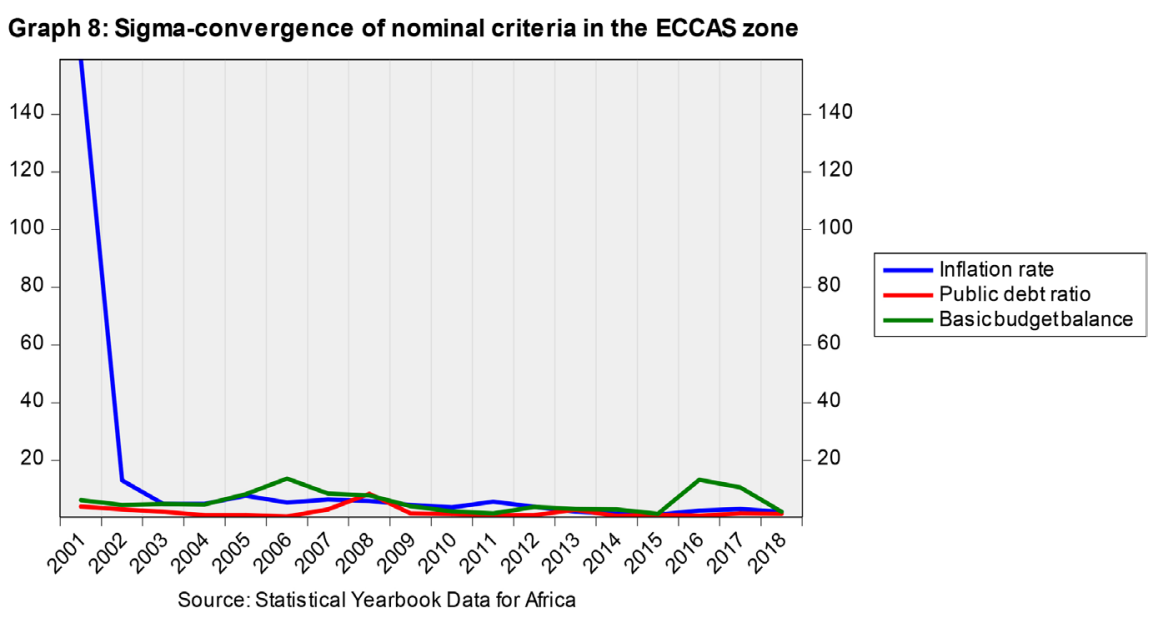


According to graph 8 above, for the variables "inflation" and "public debt ratio", there is a tendency for dispersion among ECCASeconomies to decrease. Similarly, for the basic fiscal balance, the results do not show an improvement in convergence over the entire period, although a downward trend can be noted since 2016.

As regards the calculation of beta-convergence, we are inspired by the multilateral surveillance system in the CEMACzone, which is an adaptation of the European Union system. For this purpose, we use the community reference below:

- A basic budget balance (excluding grants) relative to nominal GDPthat is positive or zero;

- An average annual inflation rate less than or equal to $3 \%$;

- A public debt ratio (domestic and external) of less than 70\% of GDP.

The results obtained after estimating Equation (6) are summarized in Table 4 below.

It notes that for the inflation criterion, only Angola and the Democratic Republic of the Congo converge towards the $3 \%$ standard. For the other two criteria, the coefficients are not negative and although the significance thresholds are satisfactory, particularly for the basic budget balance in Angola, Cameroon, DRC $^{13}$, Rwanda and public debt in Gabon and DRC. The countries studied do not seem to be converging towards the standards identified.

In summary, the above results show a weak trend towards nominal convergence of the ECCAS economies. This is for the period from 2001 to 2018.

To this end, what about real convergence?

Drawing inspirationfrom neoclassical growth models, the real convergence of economies is assessed on the basis of the convergence of living standards (Nguyen, 1996). However, for its measurement, two indicators are used:Gross Domestic Product per capita (GDP/capita) and Gross National Income per capita (GNI/capita).

Table 5 and graph 9 below present some results.

Graph 9: Sigma-convergence of living standards in the ECCAS zone

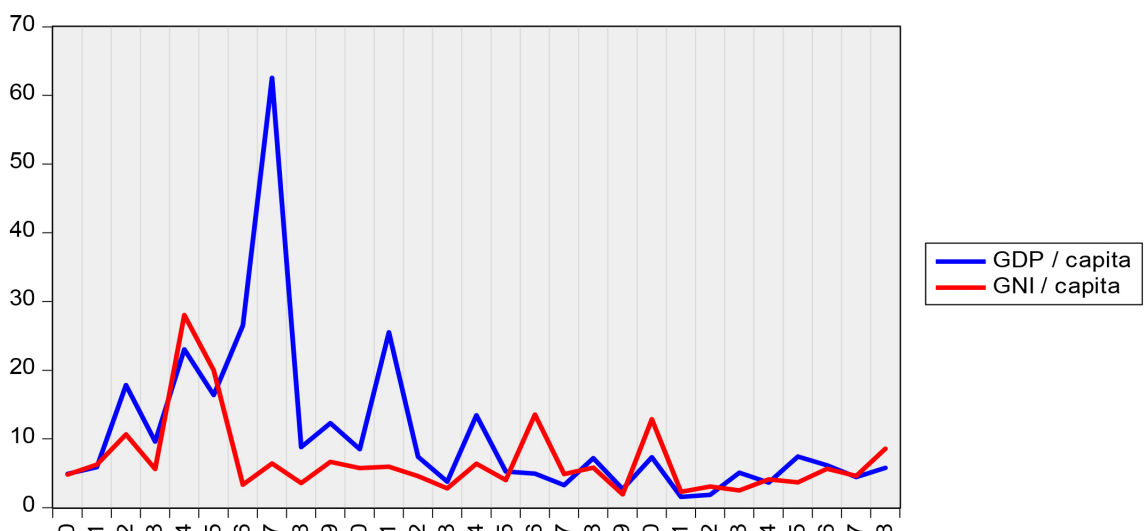

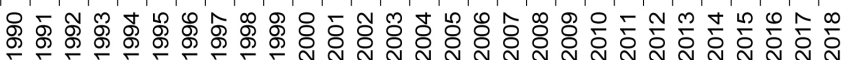

Source: World Bank 2019

${ }^{13}$ Democratic Republic of Congo. 
Table 5. Sigma-convergence applied to real indicators.

\begin{tabular}{ccccccc}
\hline Sigma-convergence & 2001 & 2006 & 2008 & 2011 & 2016 & 2018 \\
\hline GDP/capita & 25 & 4.93 & 7.17 & 1.55 & 6.15 & 5.78 \\
GNI/capita & 5.06 & 13.52 & 5.78 & 2.29 & 5.65 & 7.43 \\
\hline
\end{tabular}

The results indicate a fairly pronounced divergence in the period prior to 2008. However, from 2009 onwards, the trend is reversed and an improvement in the situation can be observed.

In summary, the results obtained show that the implementation of a convergence pact and a multilateral surveillance system in the ECCAS zone could have significant effects on the convergence of economies. These results thus contribute to the consolidation of public finances and to strengthening the resilience of economies in times of economic shocks.

\section{Conclusion and Policy Implications}

This study made it possible to analyze the evolution of business cycles in the ECCAS zone over a period of 28 years, on the one hand and economic convergence, thanks to the beta and sigma convergence technique of Baumol, 1986, on the other hand.

The results obtained suggest that in the countries studied, the evolution of real activity has an asynchronous behaviour. Thus, a weak trend towards convergence, both nominal (inflation, basic budget balance, public debt ratio) and real (GDP/capita and GNI/capita) is observed. This overall behavior can be explained by disparities of an economic (natural and demographic endowments), cultural and societal (society, history and local currency) nature. Moreover, the Covid19 pandemic has brought to light this vulnerability of ECCAS economies characterized by a low resilience capacity and the inefficiency of macroeconomic stabilization policies.

To this end, the ECCAS region requires first and foremost for its smooth functioning and developing a perfect economic and monetary integration of its member countries. This integration requires the existence of a single currency with regard to the effectiveness of monetary policy in the presence of asymmetric shocks, on the one hand, and the harmonization of budgetary policies through the establishment of a federal budget for the coordination of economic policies in times of crisis, on the other.

Therefore, for the eleven ECCAS member economies, a multilateral surveillance mechanism should be put in place, notably through the definition of nominal convergence criteria.

\section{Conflicts of Interest}

The author declares no conflicts of interest regarding the publication of this paper. 


\section{References}

Bamba, L. (2004). Analysis of the Convergence Process in the WAEMU Zone. Research Paper 2004/18, WIDER.

Barro, R., \& Sala-i-Martin, X. (1990). Economic Growth and Convergence across the United States. National Bureau of Economic Research Working Paper No. 3419. https://doi.org/10.3386/w3419

Baumol, W. (1986). Productivity Growth, Convergence, and Welfare: What the Long-Run Data Show. American Economic Review, 76, 1072-1085.

Bénassy-Quéré, A., Coeuré, B., Jacquet, P., \& Pisani-Ferry, J. (2004). Economic Policy, De Boeck University.

Calderon, C., Chong, A., \& Stein, E. (2003). Trade Intensity and Business Cycle Synchronization: Are Development Countries Any Different? Working Paper No. 478, Inter-American Development Bank.

Carmignani, F. (2010). Endogenous Optimal Currency Areas: The Case of the Central African Economic and Monetary Community. Journal of African Economies, 19, 25-51. https://doi.org/10.1093/jae/ejp016

Carree, M. A., \& Klomp, L. (1997). Testing the Convergence Hypothesis: A Comment. Review of Economics and Statistics, 79, 683-686.

https://doi.org/10.1162/003465397557114

Chen, X., \& Mills (2009). Evaluation of the Synchronization of Business Cycles in the Euro Zone. French Journal of Economics, 24, 165-185. https://doi.org/10.3917/rfe.094.0165

Creel, J. (2018). Convergence in EMU: What and How? EU Parliament In-Depth Analysys-Requested by the ECON Committee.

Duval, R., Cheng, K., Hwa Oh, K., Saraf, R., \& Seneviratne, D. (2014). Trade Integration and Business Cycle Synchronization: A Reappraisal with Focus on Asia. IMF Working Paper, WP/14/52. https://doi.org/10.5089/9781475522464.001

Ekomie, J. J. (1999). Convergence within the Economic and Monetary Community of Central Africa (CEMAC). Economic and Management Review, 1, 47-67.

Frankel, J. A., \& Rose, A. K. (1998). The Endogeneity of the Optimum Currency Area Criteria. Economic Journal, 108, 1009-1025. https://doi.org/10.1111/1468-0297.00327

Fuss, C. (1999). Convergence Measurement and Testing: A Review of the Literature. OFCE Review, 69, 221-249. https://doi.org/10.3406/ofce.1999.1546

Kane, C. S. (2013). Synchronization of Business Cycles of Industrial Production in the WAEMU. Journal of Applied Economics, the LEA Journal, 1, 179-198.

Krugman (1993). Lessons of Massachusetts for EMU. In F. Giavazzi (Ed.), Adjustment and Growth in the European Monetary Union (pp. 241-261). Cambridge: Cambridge University Press. https://doi.org/10.1017/CBO9780511599231.016

Mankiw, G. N., Romer, D., \& Weil, D. N. (1992). A Contribution to the Empirics of Economic Growth. Quarterly Journal of Economics, 107, 407-438.

Martin, C., \& Velazquez, F. (2001). An Assessment of Real Convergence of Less Developed EU Members: Lessons for the CEEC Candidates. European Economy Group Working Paper $n^{\circ}$ 5/2001.

Nguyen, K. (1996). Real Convergence in Europe. BNP Business Newsletter, February. Paper 2004/18, WIDER.

Penot, A., Polin, J.-P., \& Seltz, V. (2000). Heterogeneity of the Euro Zone and Single 
Monetary Policy. Paper Presented at the 17th Journées du GdR Economie Monétaire et Financière, Lisbon.

Rodrik, D. (2014). An African Growth Miracle? In Richard H. Sabot (Ed.), Ninth Annual Conference, Washington DC: Center for Global Development.

Tornell, A., \& Lane, P. (1999). The Voracity Effect. American Economic Review, 89, 22-46.

Watson (1994). Business Cycle Durations and Postwar Stabilization of the U.S. Economy. American Economic Review, 84, 24-46. 


\section{Appendix 1: Business Cycles of ECCAS Countries}

Graph1: Business cycle in Angola

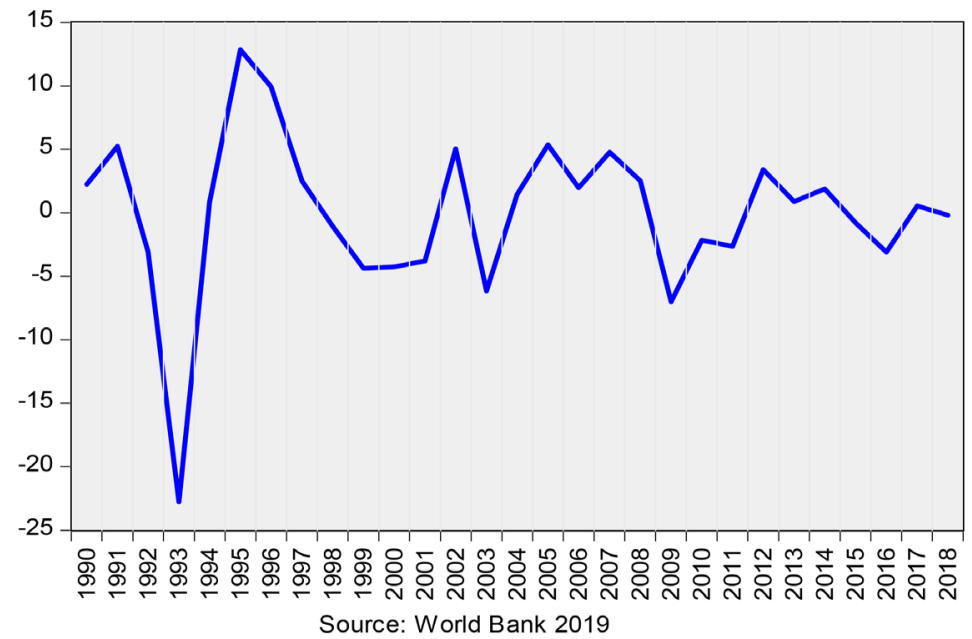

Graph 2: Business cycle in Cameroon

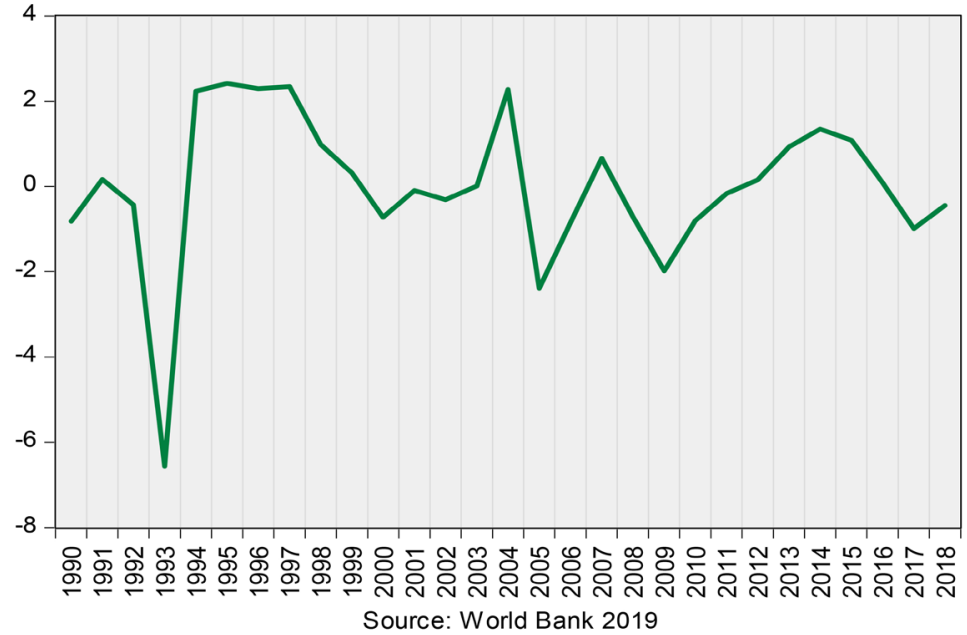

Graph 3: Business cycle in Gabon

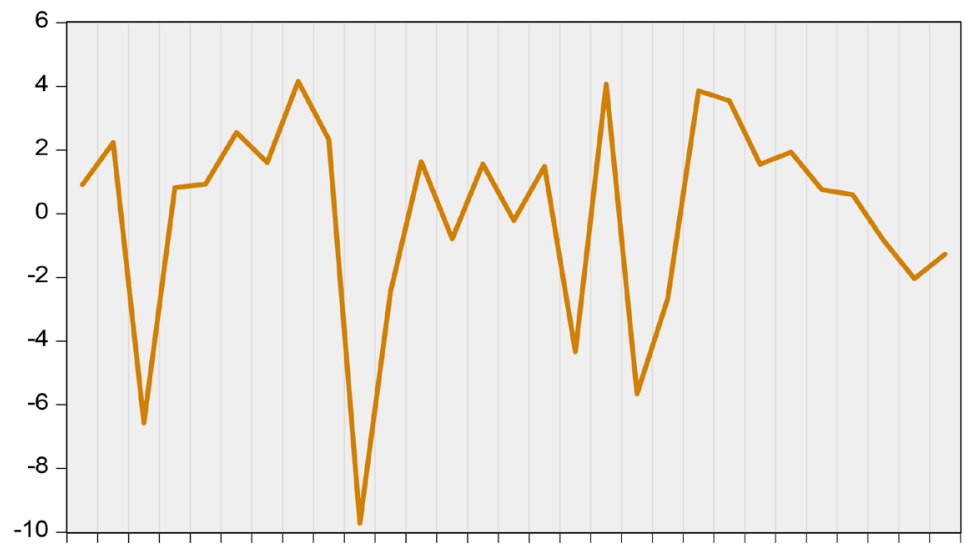

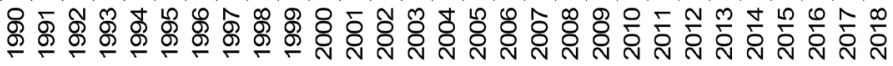

Source: World Bank 2019 


\section{Graph 4: Business cycle in Equatorial Guinea}

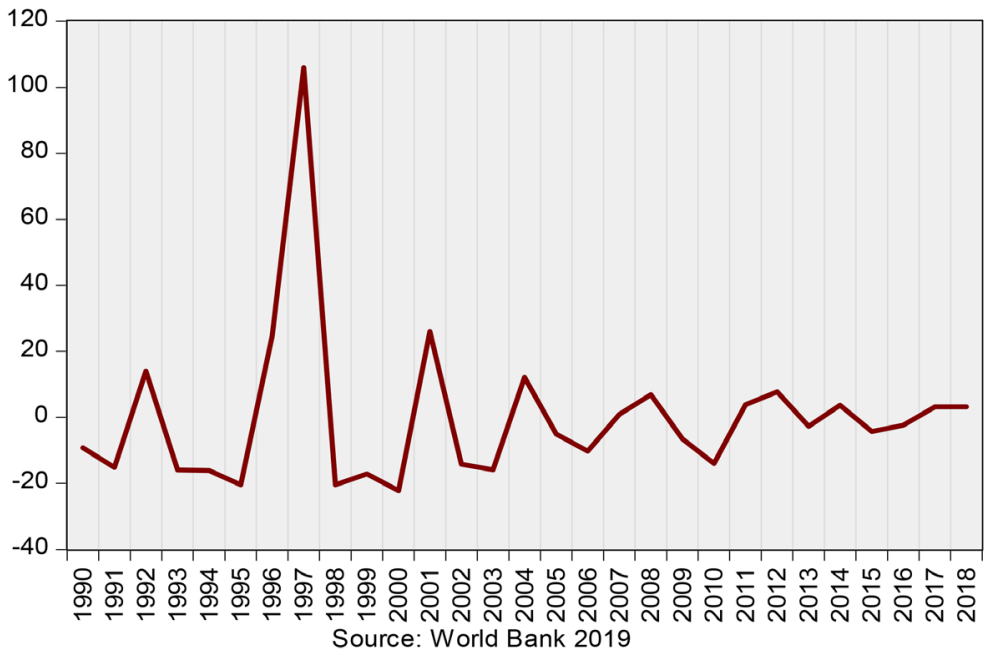

Graph 5: Business cycle in the DRC

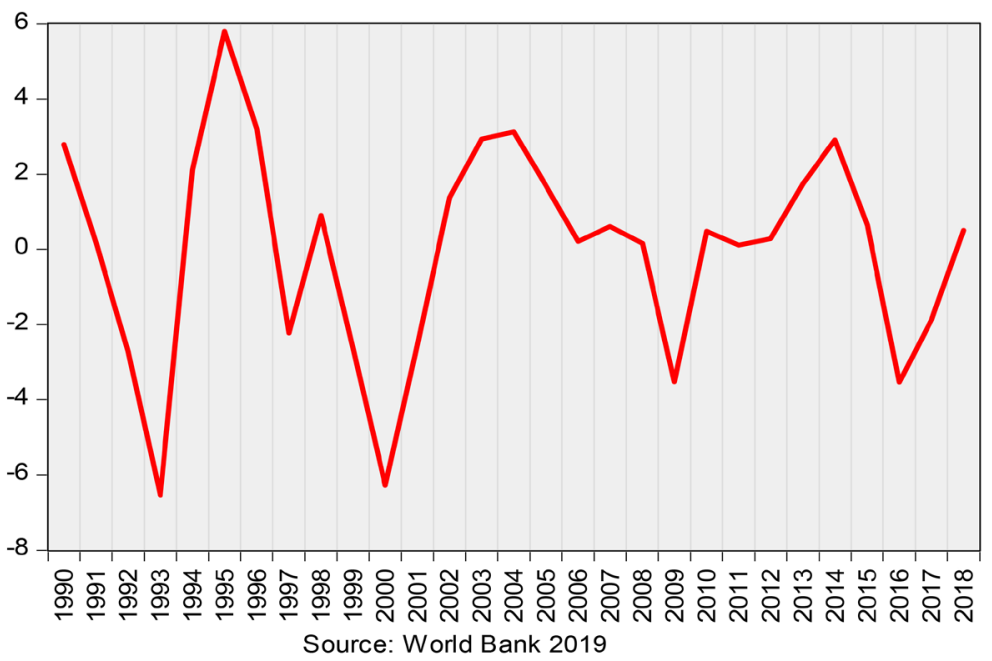

Graph 6: Business cycle in Rwanda

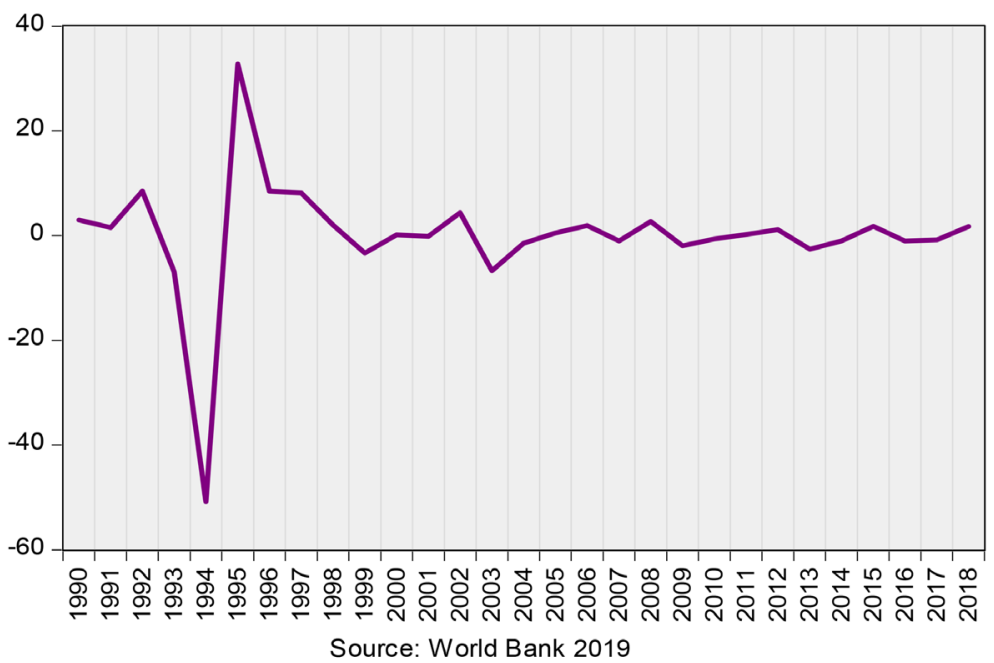




\section{Appendix 2: Dating of Business Cycles by Country}

\begin{tabular}{|c|c|c|c|c|c|c|}
\hline Angola & & & & & & \\
\hline Business cycles & peaks & hollow & Recession & Depth & Duration & Severity \\
\hline 1 & 1991 & 1993 & 1991-1993 & 25.19 & 2 & 25.19 \\
\hline 2 & 1995 & 1999 & 1995-1999 & 0.85 & 4 & 1.71 \\
\hline 3 & 2002 & 2003 & $2002-2003$ & 0.64 & 1 & 0.32 \\
\hline 4 & 2007 & 2009 & 2007-2009 & 0.94 & 2 & 0.94 \\
\hline 5 & 2014 & 2016 & 2014-2016 & 1.53 & 2 & 1.53 \\
\hline \multicolumn{7}{|l|}{ Cameroon } \\
\hline Business cycles & peaks & hollow & Recession & Depth & Duration & Severity \\
\hline 1 & 1991 & 1993 & 1991-1993 & -1.08 & 2 & -1.08 \\
\hline 2 & 1997 & 2000 & $1997-2000$ & 0.32 & 3 & 0.48 \\
\hline 3 & 2007 & 2009 & 2007-2009 & 0.55 & 1 & 0.28 \\
\hline 4 & 2014 & 2017 & 2014-2017 & 0.34 & 3 & 0.51 \\
\hline \multicolumn{7}{|l|}{ Gabon } \\
\hline Business cycles & peaks & hollow & Recession & Depth & Duration & Severity \\
\hline 1 & 1991 & 1992 & 1991-1992 & 1.51 & 1 & 0.75 \\
\hline 2 & 1997 & 1999 & 1997-1999 & 2.56 & 2 & 2.56 \\
\hline 3 & 2007 & 2008 & $2007-2008$ & 1.55 & 1 & 0.78 \\
\hline 4 & 2010 & 2017 & 2010-2017 & 0.93 & 7 & 3.26 \\
\hline \multicolumn{7}{|l|}{ Equatorial Guinea } \\
\hline Business cycles & peaks & hollow & Recession & Depth & Duration & Severity \\
\hline 1 & 1992 & 1995 & 1992-1995 & 0.50 & 3 & 0.75 \\
\hline 2 & 1997 & 1998 & 1997-1998 & 0.84 & 1 & 0.42 \\
\hline 3 & 2001 & 2003 & $2001-2003$ & 0.78 & 2 & 0.78 \\
\hline 4 & 2008 & 2010 & 2008-2010 & 1.50 & 2 & 1.50 \\
\hline \multicolumn{7}{|c|}{ Démocratic Républic of Congo } \\
\hline Business cycles & peaks & hollow & Recession & Depth & Duration & Severity \\
\hline 1 & 1995 & 1997 & 1995-1997 & 9.02 & 2 & 9.02 \\
\hline 2 & 1998 & 2000 & $1998-2000$ & -3.26 & 2 & -3.26 \\
\hline 3 & 2004 & 2009 & 2004-2009 & 0.58 & 5 & 1.44 \\
\hline 4 & 2014 & 2016 & 2014-2016 & 0.75 & 2 & 0.75 \\
\hline \multicolumn{7}{|l|}{ Rwanda } \\
\hline Business cycles & peaks & hollow & Recession & Depth & Duration & Severity \\
\hline 1 & 1992 & 1994 & 1992-1994 & 9.56 & 2 & 9.56 \\
\hline 2 & 1995 & 2003 & $1995-2003$ & 0.94 & 8 & 3.75 \\
\hline
\end{tabular}




\section{Appendix 3: Panel Unit Root Test}

Unit Root Test in Panel: Summary

Series: inflation rate

Sample: 20012018

Méthods

Statistics

Prob.**

sections

Obs

Null hypothesis: individual unit roots

Im, Pesaran and Shin W-stat

$-2.86181$

0.0021

ADF - Fisher Chi-square

29.1951

0.0037

PP - Fisher Chi-square

66.4672

0.0000

6

100

Unit Root Test in Panel: Summary

Series: Public debt ratio

Sample: 20012018

Méthods

sections

Obs

Null hypothesis: individual unit roots

Im, Pesaran and Shin W-stat

$-1.69683$

0.0449

6

ADF - Fisher Chi-square

19.9141

0.0687

6

PP - Fisher Chi-square

47.5614

0.0000

6

102

Unit Root Test in Panel: Summary

Series: Basic Budget Balance

Sample: 20012018

Méthods

Statistics

Prob.**

sections

Obs

Null hypothesis: individual unit roots

Im, Pesaran and Shin W-stat

$-0.70730$

0.2397

6

96

$\mathrm{ADF}$ - Fisher Chi-square

16.5136

0.1688

6

PP - Fisher Chi-square

15.5286

0.2138

6

102

** Probabilities for Fisher tests are computed using an asymptotic Chi

-square distribution. All other tests assume asymptotic normality.

Unit Root Test in Panel: Summary

Series: D(Basic Budget Balance)

Sample: 20012018

Méthods

Statistics

Prob. ${ }^{* *}$

sections

Obs

Null hypothesis: individual unit roots

Im, Pesaran and Shin W-stat

$-5.38766$

0.0000

6

90

ADF - Fisher Chi-square

49.9115

0.0000

6

90

PP - Fisher Chi-square

141.645

0.0000

6

96 